\title{
Data Protection and Sample Management in Biobanking - A legal dichotomy
}

\author{
TOBIAS SCHULTE IN DEN BÄUMEN ${ }^{1}$, DANIELE PACI, DOLORES \\ IBARRETA $^{2}$
}

\begin{abstract}
Biobanking in Europe has made major steps towards harmonization and shared standards for the collection and processing of data and samples stored in biobanks. Still, biobanks and researchers face substantial legal difficulties in the field of data protection and sample management. Data protection law was harmonized almost 15 years ago while rights in samples fall under the competence of the Member States of the EU. Despite the Data Protection Directive the field of data protection shows a substantial degree of deviation as public health was excluded from the harmonization. Biobanks seem to have substantially fewer difficulties to cope with in terms of the legal requirements in the field of sample management. This paper discusses the legal framework, experiences of different biobanks in Europe and potential ways forward. It also highlights the need for a health economic analysis of the costs and benefits of privacy protection in Europe. At the moment, policymakers seem to build their decisions on an insufficient evidence base which underestimates the potential value of biobanks for European public health. Within the past few years little progress has been achieved with regards to the development of a unified legal framework in Europe, The diversity in the legal system is also reflected in the different approaches of ethics committees towards biobanking. To secure the responsible and effective use of data and samples, more efforts are needed to come up with pathways for a solution.
\end{abstract}

\section{Introduction}

According to the OECD Guidelines, ${ }^{3}$ human biobanks and genetic research databases are structured resources that can be used for the purpose of genetic research which include: a) human biological materials and/or information generated from the analysis of the same; and b) extensive associated information. These research infrastructures have a high impact potential for public health and medicine, as new drug discovery and the development of so-called personalised medicine depend on the study of large collections of epidemiological, clinical and biological samples and information from large numbers of patients and healthy persons. ${ }^{4,5}$

In March 2007 in Sevilla, the Institute for Prospective Technology Studies (IPTS), one of the seven institutes of the Joint Research Centre of the European Commission, and the Public Health Genomics European Network hosted the first workshop specifically addressing data protection issues in European biobanking. In January 2010, experts from academia, industry and the European Commission convened in Sevilla again to discuss the development of the field in the previous three years. In the meantime, both biobanking and the science which uses biobanks made substantial progress. New disease-specific and population-based biobanks have been set up in Europe and around the globe. While the need for biobanks was still a matter for debate in 2007 , there is now overall agreement in the research community that

Genomics, Society and Policy, Vol.6, No.1 (2010) ISSN: 1746-5354

(C) ESRC Genomics Network. 
biobanks are important tools for modern health research. ${ }^{6}$ This research in the field of genomics and systems biology is by nature a global enterprise which needs a global research infrastructure. The exchange of data and samples is vital for the future development of a modern knowledge society in the life sciences and public health. In this context, the legal framework for research and biobanks is of pivotal importance for the long-term sustainability of the biobanking enterprise and the success of Europe as a leading region for health research in the world. ${ }^{7,8}$

Both the normative sciences and the life sciences highlight privacy and data protection as core areas of the discourse. ${ }^{9}$ Researchers in the basic sciences and in clinical research may perceive privacy and data protection as limiting factors while normative sciences stress the importance of privacy and informational selfdetermination as indispensable conditions of freedom in the information society. ${ }^{10}$ The normative sciences, and in particular the field of public health genomics, aim to facilitate a discourse which, one would hope, proves that we do not face a trade-off between research as a collective good and privacy as a fundamental right. In this paper the current state of biobanking and the legal framework will be highlighted before the lack of economic evaluations is discussed. Finally, ways to move forward and opportunities for the exchange of samples and data are studied.

\section{Trends in biobanking in Europe}

In 2006 the IPTS conducted a survey of biobanks in Europe. ${ }^{11}$ The survey results paint a comprehensive portrait of biobanking activities in Europe: 145 active biobanks were identified and 72 per cent replied to the questionnaire (a total of 126 in 23 countries). A more recent compilation, which may not follow the same methodological approach, can be found on the websites of international and European projects and networks. ${ }^{12}$

According to the existing data, there has been acceleration in biobanking activities in recent years in Europe. While a few of the biobanks identified started collecting data in the 1970s, many more have been established relatively recently (during the 1990s), with 37 per cent of the surveyed biobanks starting their activity after 2000 , obviously reflecting the burst of genome-wide association studies and the search for disease susceptibility genes and diagnostic biomarkers following the completion of the human genome sequencing project. The majority of the biobanks do not foresee an end to their sampling activities and indicate a high potential for growth, showing the dynamic nature of biobanking and an increasing role in research.

About 80 per cent of the surveyed biobanks are public collections based either at universities or national/regional agencies and have been set up either for populationbased or disease-specific research purposes. Most of the collections are either smallor medium-sized and consist primarily of DNA, serum and whole blood and/or cellular tissue samples, and several types of associated data including medical, demographic, genetic and environmental.

Interestingly, almost 70 per cent of the surveyed biobanks were single collections (ie not forming part of a network or partnership) with database systems which, in most cases, were stand-alone. In addition to this limited networking, at least in terms of

Genomics, Society and Policy, Vol.6, No.1 (2010) ISSN: 1746-5354

(C) ESRC Genomics Network. 
existing database infrastructures, only about half of the biobanks participating in the survey indicated they have a policy for sharing samples across borders either within the EU or worldwide. Nevertheless, access to the biobank is, in most cases, either entirely free or restricted to a part of the repository. Fees for granting access to samples and/or data apply to about a third of the cases. Yet scientific collaborations between biobanks are prominent. Eighty-five per cent of the survey respondents reported at least two collaborations with other researchers and 45 per cent reported more than 10. Moreover, 52 per cent of the biobanks surveyed are involved in international collaborations.

Significant variability emerged with regards to privacy and data protection requirements among biobanks in Europe. The present survey demonstrates that the majority of biobanks have at least one type of consent form that allows tissue (63.5 per cent) and data (69 per cent) sharing. Yet a significant proportion of them utilise more than one type of consent depending on the sample. The use of samples defined in the consent form is also highly varied, ranging from research on specific diseases to blanket (as practiced for example in the case of the UK Biobank). Importantly, 13 respondents indicated that they do not apply consent at all. ${ }^{13}$ Six of them belong to Eastern European Countries with the rest based in Western Europe.

Such differences have been observed previously and may be partly attributed to the varied interpretation and implementation of EC directives, and in particular the Data Protection Directive, EC Directive 95/46/EC, ${ }^{14}$ covering aspects of biobanking by national authorities. One of the main complications is that, although the field of data protection is harmonised through the EC directives, the collection, storage and sharing of samples is not. Furthermore, in countries that have introduced special biobanks acts it is not always clear where the borderline lies between the scope of these acts and that of the Directive. There seems to be a trend to break down this sample/data dichotomy and to consider under "database" both the physical sample and the information derived from it, but a deeper international understanding and agreement still need to be reached.

As will be discussed, the variability found with regards to privacy and data protection requirements might reflect diverse interpretations of the $\mathrm{EC}$ directives by national authorities. However, it should be noted that, according to the survey, biobanks within the same country reported different practices, suggesting that the problems of harmonization might be greater than expected or acknowledged. Not only are there different national laws, but apparently even within EU Member States biobanks do not implement homogenous practices on privacy and data protection issues.

The role of research ethics committees is, in this context, gaining increasing importance, as shown by the large majority of the biobanks surveyed which are governed by an ethics board ( 86 per cent). Properly addressing the ethical issues raised by vast biobanking projects can determine the successful clinical uptake of genomics. It is therefore important to understand how the different biobanks are dealing with these issues in practice.

Genomics, Society and Policy, Vol.6, No.1 (2010) ISSN: 1746-5354

(C) ESRC Genomics Network. 


\section{The Data Protection Directive}

At the very heart of European data protection legislation is EC Directive 95/46/ECon the protection of individuals with regard to the processing of personal data and on the free movement of such data. It has been transposed into national law ${ }^{15}$ and serves as the basis for the national Data Protection Acts of all EU member states. Its objective is to secure the free flow of personal data within the internal market while ensuring a high level of protection for all citizens. Within the Directive and the national laws different categories of data exist which follow different regulatory pathways. These different pathways are also reflected in the 2009 OECD Guidelines on Human Biobanks and Genetic Research Databases. ${ }^{16}$, Health data are highly sensitive and therefore require a high level of protection. ${ }^{17}$ Health data are more than just data processed in the medical and health services. The categorisation depends on the purpose of the data processing; for example, data which have been collected to assess the socio-economic status of a person or which measure the exposure to environmental risks become health data if they are processed to study commoncomplex disorders or health related behaviour. Health data hold a special position within the Directive: the processing of sensitive data in general is prohibited (Article 8). Still, the protection is not absolute and there are circumstances where the public interest overrides the privacy interests of the individual. For this reason some exemptions to the general prohibition to process health data are foreseen in the Directive. Biobanks as an infrastructure for research were still unknown at the time the Directive was drawn up, so it is not easy to find the right category for them. Biobanks are not research themselves but they belong to the wider research domain. Biobanks for health research can also be seen as public health tools as they share many legal features with monitoring and surveillance institutions. ${ }^{18}$

Biobanks are not explicitly mentioned in Article 8; but the following paragraphs provide (or might provide) exemptions to the general processing prohibition relevant for biobanks and medical research:

Paragraph 2 (a): the data subject has given his explicit consent to the processing of those data, except where laws of the Member State provide that the prohibition referred to in paragraph 1 (prohibition of processing of sensitive data) may not be lifted by the data subject's giving his consent

Paragraph 3: processing of person identifiable health data is allowed where this processing is required for the purpose of preventive medicine, medical diagnosis, the provision of care or treatment or the management of health-care services, and where those data are processed by a health professional subject, under national law or rules established by national competent bodies, to the obligation of professional secrecy, or by another person also subject to an equivalent obligation of secrecy.

Paragraph 4: subject to the provision of suitable safeguards, Member States may, for reasons of substantial public interest, lay down exemptions in addition to those laid down in paragraph 2 either by national law or by decision of the supervisory authority.

(C) ESRC Genomics Network. 
Recital 34 to the Directive ${ }^{19}$ is related to Article 8(4). Here public health is explicitly mentioned, as being a legitimate ground for Member States to derogate from the prohibition on the processing of sensitive data.

The implementation of the Directive in the Member States was monitored by the Directorate-General for Freedom, Security and Justice until a new division of responsibilities brought it under the aegis of the Directorate-General for Justice and Fundamental Rights. The first implementation report was published in $2003 .{ }^{20}$ The general conclusion was that there was no need for legislative change, although there was considerable scope for improvement in implementing the Directive. Currently a revision of the Directive is under discussion but the discourse is in an embryonic state and no conclusion can be made for the future of biobanking.

\section{III.2. The principles behind the Data Protection Directive}

\section{III.2.1. The concept of purpose}

The concept of purpose is the basis of data protection and information rights in Europe as it serves as a litmus test for the legitimacy of data processing (including the sharing and linking of data).

The principle of purpose, in combination with the principles of non-excessiveness and fairness, with regard to data collections like biobanks is described in Recital 28 and in Article 6 para 1(b) of the Data Protection Directive. The wording of the Recital is:
Whereas any processing of personal data must be lawful and fair to the individual concerned; whereas, in particular, the data must be adequate, relevant and not excessive in relation to the purposes for which they are processed: whereas such purposes must be explicit and legitimate and must be determined at the time of collection of the data; whereas the purposes of processing further to collection shall not be incompatible with the purposes as they were originally specified (our emphasis)

The Recital highlights the data protection problems that biobanks are currently facing in the legal discourse. Large-scale population-based biobanks require substantial investments and are part of a long-term infrastructure for medical research. Accordingly, from the research perspective, the purpose is exactly to serve as a tool for long-term genome-based research. ${ }^{21}$ The Data Protection Directive states that the purpose of the processing must be legitimate and explicit at the time of the data collection.

Not all biobanks are the same and the IPTS study clearly shows that small biobanks need to be taken into consideration as well: small size (e.g. university hospitals) and mid-size (e.g. pharmaceutical companies or disease-specific biobanks) biobanks which serve a specific research task face fewer difficulties in identifying a purpose in the sense of the Directive but they encounter other legal problems, such as access to information rights and return of information duties. The purpose issue has to be reconsidered once a small biobank enters into a virtual biobanking network or becomes an integral part of a bigger biobank. In contrast, large-scale biobanks may be

Genomics, Society and Policy, Vol.6, No.1 (2010) ISSN: 1746-5354

(c) ESRC Genomics Network. 
unable to define a specific scientific purpose at the time of the collection of data as they are open for various research protocols. The Directive does not provide an answer to the question whether the creation of an infrastructure for future genomic research is a legitimate, specific and explicit purpose. Large-scale biobanks tend to soften the privacy objections through procedural regulations and internal institutions which aim to guarantee a high level of privacy protection. Such surrogate solutions are widely accepted by politicians and donors, but still have to pass the litmus test of the Directive.

The Directive itself acknowledges open purposes, as in Recital $34^{22}$ where derogations are allowed from the prohibition of processing on grounds of public health and social security. The exemption for scientific research in Recital $29^{23}$ only applies to the "further processing" of data and does not apply to the original data collection. An exemption which could be used by biobanks is the exemption foreseen in Art 8 para 3 with Recital $33^{24}$, which allows processing without an informed consent "for certain health-related purposes". The applicability of Art 8 (3) is questionable, however, as the materials of the legislation process indicate that this exemption shall cover individual health purposes and the management of the health care system only. ${ }^{25}$ Therefore Recital 34 and the corresponding exemption of Art 8 (4) need to be seen as the only legal basis for biobanks in the Directive. For political reasons Art 8 (4) is not harmonizing as it enables Member States to make exemptions:

Subject to the provision of suitable safeguards, Member States may, for reasons of substantial public interest, lay down exemptions in addition to those laid down in paragraph 2.

While the Directive enables Member States to set up regulations which enable biobanks to achieve their goals, there is no harmonised legal situation in Europe. Member States are not obliged to use Art 8 (4) for biobanking purposes and if they do, they still have discretion how and to what extend they use it. The Directive also empowers Member States to define divergent safeguards which may force biobanking networks and multi-centre research studies using biobanks to follow a "gold standard" (in this case the strictest regulatory environment) approach whenever they want to transfer data.

\section{III.2.2 The concept of informational self-determination and informed Consent}

Privacy is often seen as the underlying concept of data protection policies in Europe. Yet privacy has different dimensions and, in particular with regards to data protection, also different roots in Europe. While privacy was originally seen as a right to be left alone, in particular in the Warren/Brandeis paper from $1890,{ }^{26}$ its meaning has undergone substantial changes in the new information society. In 1983 the German constitutional court established a "right to informational self-determination" which has influenced European data protection legislation ever since. ${ }^{27}$ This right implies that the individual shall have full knowledge about data processing processes which affect him or her. Informational self-determination serves not only the individual but also democracy and pluralism. From the idea of informational self-determination it is only a small jump to the consent model which is used in the Data Protection Directive. The concept of informational self-determination and the concept of purpose

Genomics, Society and Policy, Vol.6, No.1 (2010) ISSN: 1746-5354

(C) ESRC Genomics Network. 
interact in this context. To assess whether the collection of data and its further processing is necessary and proportionate, the purpose of the biobank must be taken into consideration. The definition of informed consent in the Data Protection Directive seems to support this view, as Art 2 (h) reads:

The data subject's consent shall mean any freely given specific and informed indication of his wishes by which the data subject signifies his agreement to personal data relating to him being processed. (our emphasis)

The consent in data protection must be purpose-specific and informed, two prerequisites which are affiliated with each other, as the purpose also determines the content of the disclosure and information duties. This is important as many biobanks favour an open or blanket consent. Open or blanket in this sense means that the biobank can not specify the purpose; instead the donor is asked to consent to the use of material and data for all research proposals which fall under the scope of the biobank and which pass the ethical and legal check of the biobank. An open or blanket consent allows the biobank to operate more flexibly; a specific consent procedure might force the bank to seek new donor consent for every study which wants to use data and material. Such a re-consent procedure cannot be handled by large biobanks and it also complicates the use of coding systems.

There seem to be two main arguments which endorse the concept of blanket or open consent: firstly, the consent is buffered by further safeguards and a pluralistic governance system which includes different stakeholders and, secondly, donors may also be able to execute a "right to take a risk" which is a subcategory of the overall personality right. The "right to take a risk" can be accepted as a legal basis for open/blanket consent if the donors are fully informed about the incomplete degree of information they obtain during the disclosure process. ${ }^{28}$ This right to take a risk is not yet a widely accepted concept in the biobanking community or among data protection scholars, therefore the term should be used with caution. From the perspective of the right to informational self-determination as the German Constitutional Court developed it in the "Census Decision", the open/blanket consent would still have to be deemed invalid as the donor is not put in a position where he/she can assess the future risks for privacy and the free development of the personality in the given information environment. The situation is even more complicated if the different layers of consent are considered, including the consent to sample collection and the consent to the medical research which will be carried out using the samples and data. In practice, biobanks have to manage primarily with the data protection consent if they work with samples and associated data. Any physical harm without consent must be deemed to be illegal and for the consent to research activities a broad consent is acceptable under the Directive if further safeguards protect the human subject .

The current legal system offers both options as either the "right to take a risk" or the right to informational self-determination can be stressed. Both rights derive from the same source, human dignity and personality rights, although the "right to take a risk" could be seen to be derived from the overall concept of personality rights. The "right to take a risk" in this sense is a highly individualistic approach and may not correspond easily to the overall characteristics of certain kinds of genetic information.

Genomics, Society and Policy, Vol.6, No.1 (2010) ISSN: 1746-5354

(C) ESRC Genomics Network. 
Further elaboration is also needed as to what extent such a right is acceptable if the disclosure of information creates risks for third persons (in particular minors).

Whenever the person who is consenting discloses identifiable information which relate to a second person and not solely to the person who has given the open/blanket consent, the "right to take a risk" can hardly be justified. ${ }^{29}$ Legal and ethical scholars advocating the "right to take a risk" need to work on additional concepts which enable society to govern such (potential) infringements of privacy rights of third persons.

\section{The legal status of samples}

Samples in the sense we use it here can mean various kinds of biological material including tissue, cells or blood. The legal situation of biological material varies across Europe. ${ }^{30}$ Under some legal systems, such as the German system, the donor retains property rights ${ }^{31}$ even after the biological material is permanently extracted from the body, ${ }^{32}$. while others have a different view. The English system, for example, does not apply property law to samples. ${ }^{33}$

Under the Data Protection Directive the term 'data' is defined in Art 2 (a) in relation to the data subject: "Personal data shall mean any information relating to an identified or identifiable natural person (data subject)."

Biological material, therefore, may not be seen as data under the Directive as it is not information itself. Like a hard drive, it contains data but another technical step is required to extract the data, in this case from the biological material. ${ }^{34}$ This may at first seem to be confusing. Take the example of blood. Blood is a liquid like many others and further analytical measures are needed to gain health information from the blood. The difference is even more apparent if we take the example of water; if a person drinks from a glass of water, it may be possible to extract genetic information about this person afterwards. Yet legal scholars would not even consider bringing the water under the definition of data in the Directive. Any data which accompany the samples, e.g. identification data, are of course information under the terms of the Directive.

For samples, the Data Protection Directive becomes applicable if data are extracted from biological material in a way which could identify a person or within a setting which operates with identifiers. A biobank can serve as a research infrastructure and may not encounter data protection problems if it solely stores and ships biological material to a third party without any collection or secondary processing of personal information. For biobanks and researchers the combination of samples, data deriving from samples and secondary data is the key to the success of biobanking. Thus the legal separation of data and samples may appear artificial to them. Also, among legal scholars there is a growing tendency to apply the legal framework of data protection to both samples and data. The idea has recently been endorsed by the European Court of Human Rights in the case of S. and Marper v. UK. ${ }^{35}$ This could eventually lead to a higher degree of harmonisation in Europe as the Directive governs substantial parts of the field. The European Commission does not have a direct competence to harmonize the legal framework for samples as this would affect the property rights domain. Although we face a huge diversity in the regulatory systems of samples and

Genomics, Society and Policy, Vol.6, No.1 (2010) ISSN: 1746-5354

(C) ESRC Genomics Network. 
data in Europe, it may not greatly affect the current practice of biobanking as data protection principles are frequently used as a benchmark for both data and samples.

\section{The application of a unified legal framework by ethics committees}

Medical research often requires an impartial review to make sure that research projects do not contravene ethical standards. Ethics committees, or institutional review boards (IRB) as they are called in many jurisdictions, serve this purpose. The involvement of such a committee can also help researchers to comply with the regulations of the Data Protection Directive, as Art 8 (4) / Recital 34 call for the provision of safeguards to protect the fundamental rights of data subjects. The borderline between data protection and the ethical approval of research projects is imprecise and some countries might even opt for a merger of both aspects. ${ }^{36}$ The interplay between the biobank and the recipient research group means that more than one ethics committee might be involved in the data and material transfer procedures. While the ethics committee of the recipient approves the research project, the biobank and its ethics committee may check compliance with the biobank's own regulatory and ethics framework. Consequently, legal diversity in the data protection field is potentially amplified by the ethical values enforced by the different ethics committees.

The interdisciplinarity of ethics committees guarantees that the various interests of researchers, donors and the public are balanced. One important area is the consent procedure, as the approval of an ethics committee may help to overcome the deficits of the open consent standard in biobanking, even though it cannot replace the individual consent which is based on the execution of fundamental rights. ${ }^{37}$ In the practice of biobanking, ethics committees may also act in a contrary way if they obstruct the free flow of data as intended by the Directive. ${ }^{38}$ This aspect has not been closely studied yet and needs further research. Due to its Single Market approach the Data Protection Directive forbids the erection of further hurdles for the sharing and linkage of data. Because of the rule of law doctrine and the hierarchy of norms in the legal system, this implies that neither national laws nor ethics committees are allowed to request higher standards of protection unless the higher standards are equally based on European law themselves.

As Member States are obliged to implement the Directive they are entitled to ensure that ethics committees do not unnecessarily obstruct the access to data of researchers. While Art 8 (4) of the Directive empowers Member States to set up exemptions which lift the prohibition of sensitive health information there is no such rule which allows stricter regulations.

\section{The lack of economic evaluation}

The issue of the cost of data protection is one of the arguments frequently indicated by the research community as a barrier to the development of basic science using biobanks. However, costs are often not acknowledged as a governance issue in genome-based research. It is also difficult to determine societal costs if research is not able to tap the full potential for the benefit of patients. Nevertheless, a clear analysis of the costs of data protection seems to be a necessary step to understand the actual

Genomics, Society and Policy, Vol.6, No.1 (2010) ISSN: 1746-5354

(C) ESRC Genomics Network. 
and potential impact of the Data Protection Directive, and to evaluate economic issues emerging from the application of data protection laws in Europe.

Economic impact assessment has recently become a prominent issue in several policy fields and in particular in health. ${ }^{39}$ Since economic and cost-effectiveness considerations play an important role in the translational research (from basic discoveries to normative science) and in public health decision-making, ${ }^{40}$ it might be desirable for economic analysis to be applied to the study of data protection in biobanks.

One of the core tasks of data protection is the promotion of 'information justice' which balances the individual right to privacy and the societal need for information in health research. As both the individual right to privacy and the collective/individual right to access to information have a value, they carry costs and benefits which should be carefully evaluated.

Data protection explicitly erects hurdles which influence the costs of biobanking. For the practice of biobanking, new technical solutions like the GenoMatch ${ }^{41}$ model of BayerSchering might not be affordable for small or publicly financed biobanks. The requirement of an individual disclosure to donors, which derives from the donorcentric disclosure standard in data protection, can also affect the costs of managing and using a biobank. According to preliminary estimates from BayerSchering, the costs for the triple coding procedures in GenoMatch vary between 20-30 Euros per sample. Costs of privacy protection might prohibit researchers from setting up small and midsize biobanks. These costs must be seen in relation to the expected public health benefits spinning off from the medical research made possible through the biobanks, and other intangible benefits, like public trust in health care and medical research and respect for citizens' privacy.

Moreover data protection legislation, especially if not harmonized, could increase the cost of networking and sample/data sharing, thus limiting the (currently hypothetical) benefits from genomic research which uses large transnational collection of samples.

However, data protection can also help biobanks to develop efficient procedures which might reduce costs in the long run. Moreover, from a biobank's perspective it should also consider the reduction in costs that the data protection law has on the recruitment of patients (potential donors). This should be done measuring the willingness-to-cooperate of the donors under alternative data protection regimes.

No analysis of the cost-effectiveness of data protection in biobanking has been performed or published so far. This is linked to a lack of reliable and comparable economic data on biobanking activities. Indeed, there are few estimates of the costs of biobanks because of a number of issues, including the following:

- Due to the lack of legal entity, the boundaries of biobanks for accounting purposes are difficult to define clearly.

(C) ESRC Genomics Network. 
- There are no accounting standards for biobanks' activities, so it is not always straightforward to identify the relevant unit cost (i.e. cost per collected sample or cost per released sample)

- The sensitivity to accounting and economic issues is very low among the scientists involved in the biobanks and, especially in the public ones, is not incentivised.

On the 'benefits' side it is difficult to quantify, in economic terms, the possible innovations to which a biobank could contribute. Biobanks can be considered as basic research infrastructures, and the uncertainty of their potential results is exceptionally large in terms of time and magnitude. Morevoer, the actual "production" of a biobank, it is not easily quantifiable. There is still only limited agreement on whether considering scientific publications that quote a biobank as a source of data is a good proxy for evaluating biobanks' contribution to innovation and public health.

The lack of economic data, the public nature of biobanks, and the significant positive externalities, as defined by Ertug et al, ${ }^{42}$ associated with biobank-based genomic research are all important barriers that might make it unrealistic to apply standard health economics analyses (e.g. cost-effectiveness analysis; cost-benefit analysis; cost-utility analysis) to the study of data protection in biobanks. Nevertheless, this should not limit the study of the economic implications of data protection in an important field of life science research and public health. Other types of policy impact analysis could be used to evaluate the economic impact of the Data Protection Directive on biobanks. These studies could be designed ad-hoc using survey on willingness-to-pay, under different data protection scenarios. It would be a major achievement if such a study could be conducted in the near future.

\section{The way forward}

It seems evident, and widely recognised, that biobank quality, networking, and sustainability are critical to accelerating scientific discovery in the biomedical sciences. Building and sustaining biobanking infrastructures and finding ways to maximise their scientific value and international usage have become immediate goals.

Ultimately, the success of tomorrow's biobanking activities will depend upon creative problem-solving and will require a fundamental shift from working in disparate biobanks to a collaborative infrastructure and shared access approach.

In the future, there is likely to be greater integration between the various biobank typologies (e.g., population, clinic, disease, and tissue), making data exchange more fluid between studies from isolated populations and from population-based and clinical-based biobanks

New governance structures would be required to incorporate this option into the informed consent process and to define what information would be fed back, by whom, and how. Others argue that sharing individual results is unduly burdensome and thus impractical ${ }^{43}$. They further contend that participants are most interested in knowing simply that their involvement has enhanced scientific knowledge and served the public good. 
Networking of biobanks is crucial for maximising their public health benefits. In order to be able to network these very different resources, some degree of harmonisation must be achieved. Whether this should be achieved at the level of legal/regulatory requirements and practices and/or by technical standardisation requires further investigation. Experts consulted in the IPTS study ${ }^{44}$ suggested the establishment of an international (rather than just European) umbrella (or network) organization, which would establish common operating procedures in, for example, genotyping and phenotyping, quality assurance and information management, and common approaches to ethical and legal requirements such as consent, data protection and privacy, feedback of information to donors, and so on. In this context, already existing initiatives with similar objectives should be taken into consideration. On a global level $\mathrm{p} \mathrm{g}^{45}$ and ISBER have been working in this domain and in Europe the recently established BBMRI has shown great efforts to take Europe to the next level of networking in biobanking.

\section{Conclusion}

Biomedical research in Europe still faces substantial problems when it comes to the exchange of samples and, in particular, data. While the Data Protection Directive serves as a benchmark for the exchange and flow of data, there seems to be no competence for the EU to govern the exchange of samples as this part of regulation falls under property law in many Member States. Interestingly, the problems in practice are rather observed in the field of data protection while samples are shipped routinely within the EU 27 and beyond. To some extent this situation arises from the fact that the field of public health is not harmonized in the Data Protection Directive. There is also a hypothesis that the data protection principles are interpreted differently in Member States and in particular amongst ethics committees and IRBs. This raises the question to what extent these boards and committees are empowered to set higher standards than those set out by law. In Europe, at least, such decisions should be made with respect to the overall aim of the Directive to enhance the exchange of data. Little evidence exists about the problems of commercial entities in obtaining data and samples for research. Big pharmaceutical companies run internal biobanks but apparently do not share facilities with academia. As big companies tend to operate under a global gold standard it is desirable to learn more about the procedures in industry.

Recently, several countries have set up specific regulations for biobanking, biomedical research and the use of genome-based information. For the EU Member States these new regulations also have to be interpreted and assessed by applying the principles of the Data Protection Directive. Thus, two issues need to be raised: there is a strong need for a health-economic assessment of the societal costs versus benefits of data protection in biomedical research, and there is an urgent need for a strong European, or preferably global, institution which facilitates the exchange of both samples and data. The market approach as it seems to obtain currently in the field of samples cannot be the prime option for the entire domain of biobanking, as data protection is highly regulated and institutionalised around the globe.

Genomics, Society and Policy, Vol.6, No.1 (2010) ISSN: 1746-5354

(C) ESRC Genomics Network. 
${ }^{1}$ Institute for Public Health Genomics (IPHG), School for Public Health and Primary Care (CAPHRI), Maastricht University, Correspondence to: t.sidb@maastrichtuniversity.nl

${ }^{2}$ Dolores Ibarreta and Daniele Paci are affiliated with the European Commission, Joint Research Centre (JRC), Institute for Prospective Technological Studies (IPTS). The views expressed are those of the writers and do not necessarily represent an official position of the European Commission.

${ }^{3}$ OECD. 2009. Guidelines for Human Biobanks and Genetic Research Databases, published in 2009 (00 2009 3B 1 P) - No. 89497.

${ }^{4}$ E. Zika, D. Gurwitz and D. Ibarreta, 2006. Pharmacogenetics and pharmacogenomics: state-of-theart and potential socio-economic impact in the EU. European Commission DG JRC/IPTS, EUR 22214.

${ }^{5}$ M. Yuille et al. Biobanking for Europe. Brief Bioinform 2008; 9:14-24.

${ }^{6}$ A. Brand and N. Probst-Hensch. Biobanking for Epidemiological Research and Public health, Pathobiology 2007; 74: 227-238.

${ }^{7}$ E. Zika et al. Sample, data use and protection in biobanking in Europe: legal issues.

Pharmacogenomics 2008; 9 (6): 773-781.

${ }^{8}$ M. Kapp. Biobanking Human Biological Materials: Issues Surrounding the Collection of Samples for Use in Future Research. Pharmaceutical Medicine 2008; 22 (2): 75-84.

${ }^{9}$ H. Greely. The Uneasy Ethical and Legal Underpinnings of Large-Scale Genomic Biobanks. Annual Review of Genomics and Human Genetics 2007; 8: 343-364.

${ }^{10} \mathrm{~J}$. Kaye et al. Data sharing in genomics - re-shaping scientific practice. Nature Reviews Genetics 2009; 10 (5): 331-335.

${ }^{11}$ E. Zika et al. A European survey on biobanks: trends and issues. Public Health Genomics 2010.

Online first: http://content.karger.com/produktedb/produkte.asp?doi=296278.

${ }^{12}$ In particular the BBMRI Portal; as of 22 January 253 biobanks are registered here: http://bbmri.eu/index.php/catalog-of-european-biobanks

${ }^{13}$ J. Allen and B. McNamara. Reconsidering the value of consent in biobank research. Bioethics 2009; online first: http://onlinelibrary.wiley.com/doi/10.1111/j.1467-8519.2009.01749.x/abstract

${ }^{14} \mathrm{http}$ ://ec.europa.eu/justice home/fsj/privacy/law/index en.htm

15 Commission of the European Communities. First Report on the Implementation of the Data

Protection Directive; 2003. http://eur-

lex.europa.eu/LexUriServ/LexUriServ.do?uri=COM:2003:0265:FIN:EN:PDF

${ }^{16} \mathrm{http}: / /$ www.oecd.org/dataoecd/41/47/44054609.pdf

${ }^{17}$ L. Lehtonen. 2004. Genetic Information and the Data Protection Directive of the European Union. In The Data Protection Directive and Medical Research Across Europe. D. Beyleveld et al, eds. Farnaham: Ashgate: $103-115$.

${ }^{18} \mathrm{M}$. Verschuuren et al. The European data protection legislation and its consequences for public health monitoring: a plea for action. Eur J of Public Health 2008; 18(6): 550-551

${ }^{19}$ In Recital 34 to the Directive, the field of public health is explicitly mentioned as a public interest which can justify an exemption to the prohibition of using sensitive health data.

http://www.cdt.org/privacy/eudirective/EU Directive .html

${ }^{20}$ Commission of the EC, op. cit. 14

${ }^{21}$ Opinion of the German Nationaler Ethikrat. 2004. Biobanks for Research: 28-31

http://www.ethikrat.org/ english/publications/Opinion_Biobanks-for-research.pdf

${ }^{22}$ Data Protection Directive, op. cit. 19

${ }^{23}$ Data Protection Directive, op. cit. 19

${ }^{24}$ Data Protection Directive, op. cit. 19

${ }^{25}$ Working Document on the processing of personal data relating to health in electronic health records (EHR), 00323/07/EN, WP 131.

http://ec.europa.eu/justice home/fsj/privacy/docs/wpdocs/2007/wp131_en.pdf

${ }^{26}$ S. Warren and L. Brandeis. The Right to Privacy, Harvard Law Review 1890; 4: 193-220.

${ }^{27}$ G. Hornung and C. Schnabel. Data Protection in Germany I: The population census decision and the right to informational self-determination. Computer Law \& Security Report 2009; 25 (1): 84-88.

http://www.sciencedirect.com/science/journal/02673649

${ }^{28} \mathrm{~J}$. Lunshof et al. From genetic privacy to open consent. Nature Reviews Genetics 2008; 9: 406-411.

${ }^{29}$ The supra-individual dimension of genetic data has also been discussed by the WP 29. The issue is discussed in more detail in the context of the right to know vs. the right not to know. See Ost, The Right not to Know, Journal of Medicine and Philosophy 1984; 9: 301-312

${ }^{30}$ R. Arneson. Property Rights in Persons. Social Philosophy and Policy 1992; 9: 201-230.

Genomics, Society and Policy, Vol.6, No.1 (2010) ISSN: 1746-5354

(C) ESRC Genomics Network. 
${ }^{31}$ E. Mand. Biobanken fuer die Forschung und informationelle Selbstbestimmung, Medizinrecht 2005; 23: $565-575$.

${ }^{32}$ For a discussion of this aspect, see Lobato de Faria. 2009. Ownership Rights in Research Biobanks: Do We Need a New Kind of 'Biological Property'? In The Ethics of Research Biobanking. J. Solbakk et al, eds. Springer: 263-276.

${ }^{33}$ For an in-depth analysis see J. Bovenberg. 2006. Property Rights in Blood, Genes and Data: Naturally Yours? Leiden: Martinus Nijhoff.

${ }^{34}$ Dammann, in S. Simitis (Ed.), Bundesdatenschutzgesetz, $§ 3$ par 5

${ }^{35} \mathrm{http}: / /$ www.bailii.org/eu/cases/ECHR/2008/1581.html

${ }_{36}$ See, $\S 29$ of the Draft of the German Law on Genetic Diagnostics, brought into parliament by the Green Party on Nov $3^{\text {rd }} 2006$, online available at http://dipbt.bundestag.de/dip21/btd/16/032/1603233.pdf

${ }^{37}$ Some critical comments go even further, arguing that ethics committees serve as an appeasement of societal concerns. See, for example, K. Hoyer and R. Tutton. Ethics was here: Studying the languagegames of ethics in the case of UK Biobank. Critical Public Health, 2005; 15: 385 - 397.

${ }^{38}$ E. Garrard and A. Dawson. What is the role of the research ethics committee? Paternalism, inducements, and harm in research ethics. J Med Ethics 2005: 31: $419-423$.

${ }^{39}$ M. Drummond et al. 2005. Methods for the Economic Evaluation of Health Care Programmes. Oxford: Oxford University Press.

${ }^{40}$ D. Paci and D. Ibarreta. Economic and Cost-Effectiveness Considerations for Pharmacogenetics Tests: An Integral Part of Translational Research and Innovation Uptake in Personalized Medicine. Current Pharmacogenomics and Personalized Medicine, 2009; 7 (4): 284-296.

${ }^{41}$ For an online introduction to the system see http://www.tembit.de/fileadmin/Animation/genomatch.html

${ }^{42}$ G. Ertug, C. Galunic and M. Gargiulo. Adding Value to Others: The Positive Externalities of Social Capital. 2006. Research Collection Lee Kong Chian School of Business. Paper 1279.

http://ink.library.smu.edu.sg/lkcsb_research/1279

${ }^{43}$ A more elaborated analysis has been provided by J. Bovenberg et al. Biobank Research: Reporting Results to Individual Participants. European J of Health Law 2009; 16: 229-247.

${ }^{44}$ E. Zika et al. Biobanks in Europe: Prospects for Harmonisation and Networking. JRC Scientific and Technical Reports. Sevilla, 2010

45 http://www.p3g.org/ 